Hospital in the five years prior to the study commencing. Less than half $(49 \%)$ of our study sample were in regular contact with a psychiatrist (see Lang et al, 1997, Table 1).

We would agree with Dr Simpson that the development of a comprehensive primary care record for patients with schizophrenia would be a welcome advance. We are of the opinion, however, that if people other than GPs are to contribute to such records, it is essential that a standardised method of recording consultations in the primary care setting is devised.

We agree with Dr Simpson that alcohol misuse in both younger and older people with schizophrenia significantly contributes to the difficulties which arise in patient management, but we did not find that a past history of alcohol misuse was independently related to whether or not a patient was considered by the GP as causing a problem for the practice.

Lang, F. H. Forbes, J. F., Murray, G. D., et al (1997) Service provision for people with schizophrenia: I. clinical and economic perspective. British journal of Psychiatry, 171 . 159-164.

F. H. Lang Department of Psychiatry, Kennedy Tower, The Royal Edinburgh Hospital, Morningside Park, Edinburgh EHIO 5HF

\section{Lethal lithium poisoning with sustained-release preparations}

Sir: Cookson (1997) and Moncreif (1997) have mentioned serious toxicity and death as a consequence of lithium intoxication. It would be useful to stress that more serious poisoning usually occurs after intoxication by sustained-release lithium preparations.

In 27 years of lithium medication in Southern Moravia, four cases of lethal intoxication have been reported, three of them suicides. All three patients took a high dose of the sustained-release lithium product. In two cases, the approximate doses were known ( 50 and $70 \mathrm{~g}$ lithium). In one case, the dose has not been established. Two of the patients died on the fifth day and the other died on the 12th day after taking the lethal dose of lithium. In one of the patients, the autopsy revealed undissolved lithium tablets in the stomach and the remains of tablets in the intestines, despite a gastric lavage. In another patient, high levels of lithium (34 and $11.3 \mathrm{mmol} /$, respectively) were found in the gastric lavage returns on the first and second days.
It seems that the advantage of sustained-release preparations becomes a disadvantage during intoxication. Standard gastric lavage does not remove the lithium tablets from the gastro-intestinal tract, and if they are not removed, lithium is released for a surprisingly long period of time.

One effective method, proposed by Smith et al (1991), is gastric lavage with polyethyleneglycol, which can prevent the absorption of up to $67 \%$ of the ingested lithium. Other authors recommend gastroscopy combined with aspiration, under visual control, or enterotomy to remove the tablets in addition to lavage (Olson, 1991; Ševčík et al, 1994).

Cookson, J. (1997) Lithium: balancing risks and benefits. British journal of Psychiatry, 17I, 120-124

Moncrieff, J. (1997) Lithium: evidence reconsidered. British Journal of Psychiotry, 171. 113-119.

Olson, K. R. (1991) Lithium. In Intensive Care Medicine (eds J. M. Rippe, R. S. Irwin. J. S. Alpert, et al). Boston, MA: Little. Brown and Co.

Smith, S. W., Ling, L. J. \& Halstenson, C. E. (1991) Whole bowel irrigation as a treatment for acute lithium overdose. Annals of Emergency Medicine, 20, 536-539.

Sowzik, P., Hrdilickea, M., Novotna, J., et al (1994) Current developments in the treatment of lithium intoxications. In Proceedings of the 7th European Congress on Intensive Core Medicine, pp. 903-906. Bologna: Monduzzi Editore.

M. Hrdlička Department of Psychiatry, 2nd

Medical School of Charles University, Vúvalu 84, 150 18 Prague, Czech Republic

P. Sevčik Department of Anaesthesiology, Medical School of Masaryk University, Brno, Czech Republic

\section{Tardive dyskinesia and CYP2D6 polymorphism in Chinese}

Sir: Epidemiological studies have shown a lower prevalence rate of tardive dyskinesia among Chinese than Caucasian subjects receiving neuroleptics (Swartz et al, 1997). A pharmacogenetic factor may underlie this cross-cultural difference. The study by Armstrong et al (1997) which suggests an association of neuroleptic-induced movement disorders, including tardive dyskinesia, with genetic polymorphism of CYP2D6 supports this hypothesis. About $7 \%$ of the Caucasian population lacks the CYP2D6 enzyme (i.e. poor metabolisers) compared with about $1 \%$ of the Chinese (Brosen, 1996). The majority of these Caucasian poor metabolisers have a mutant allele 2D6(B), which contains a splicing defect that is not present in a large section of the Chinese population (Brosen, 1996). New mutations have recently been reported, including the $\mathrm{Cl}$ $T_{2938}$ variation that results in one amino acid difference (R296C). This mutation, postulated to be in the putative substrate-recognition site of the CYP2D6 enzyme, also shows ethnic differences in its distributions $(26 \%$ in Caucasians, $19 \%$ in Chinese) (Wang et al, 1995). It has also been reported to be associated with Parkinson's disease (Tsuneoka et al, 1993). This is intriguing because patients with a family history of Parkinson's disease have a high risk for developing tardive dyskinesia (Swartz et al, 1997). This suggests an association of a vulnerability to tardive dyskinesia with the R296C mutation - a possibility that merits further investigation.

Armetrong, M., Daly, A. K., Blennerhassett, R., et of (1995) Antipsychotic drug-induced movement disorders in schizophrenics in relation to CYP2D6 genotype. British journal of Psychiatry, 170. 23-26.

Brosen, K. (1996) Drug-metabolism enzymes and therapeutic drug monitoring in psychiatry. Theropeutic Drug Monitoring, 18. 393-396.

Swartz, J. R., Burgorme, K., Smith, M., et al (1997) Tardive dyskinesia and ethnicity: review of the literature. Annals of Clinical Psychiatry, 9, 53-59.

Touneoka, T., Matsuo, Y., Takeuchi, H., et ol (1993) A novel cytochrome P450 IID6 mutant gene associated with Parkinson's disease. Journal of Biochemistry. I14, 263-266.

Wang, S. L., Lal, M. D., Lai, M. L., et al (1995) R296C and other CYP2D6 mutations in Chinese. Pharmocogenetics, 5. 385-388.

S.-A. Chong Woodbridge Hospital \& Institute of Mental Health, 10 Buangkok Green, Singapore 539747

\section{Evidence-based psychiatry}

Sir: The practice of evidence-based medicine has been defined as the conscientious, explicit and judicious use of current best evidence in making decisions about the care of individual patients (Sackett et al, 1996). A systematic review of randomised controlled trials can be a very useful source of evidence. The key point about a systematic review is that it has a method section which clearly states how the primary studies were identified and selected for inclusion in the review, and how their quality was assessed (Oxman et al, 1994). Neither the article by Moncrieff (1997) nor the commentary by Cookson (1997) provided this information, despite their inclusion under the heading of 'evidence-based psychiatry'. It is therefore difficult to assess the validity of these articles, and to what extent the authors attempted to avoid bias. 
We welcome the recognition of the importance of evidence-based practice by the Journal. However, we think that articles described as evidence-based should at least meet basic evidence-based criteria, which are widely available (Sackett et al, 1997). Otherwise, there is a danger that the term 'evidence-based' will simply become a fashionable label to lend undue authority to old-style articles.

Cookson, J. (1997) Lithium: balancing risks and benefits. British Journal of Psychiatry, 171, 120-124.

Moncrieff, J. (1997) Lithium: evidence reconsidered. British Journal of Psychiatry, 171, 113-119.

Oxman, A. D., Cook, D. J. \& Guyatt, G. H. (1994) Users' guides to the medical literature. VI. How to use an overview. Journal of the American Medical Association, 272, 1367-1371.

Sackett, D. L., Rosenberg, W. M. C., Gray, J. A. M., et al (1996) Evidence based medicine: what it is and what it isn't British Medical journal, 312. 71-72.

_, Richardson, W. S., Rosenberg, W. M. C., et al (1997) Evidence-based Medicine. How to Practice and Teach EBM. Edinburgh: Churchill Livingstone.

J. A. Powell, J. R. Geddes Centre for Evidence Based Mental Health, University Department of Psychiatry, Warneford Hospital, Oxford OX3 7JX

\section{Clinical trials: severe mental illness and substance misuse}

Sir: In her editorial on severe mental illness and substance misuse, Johnson (1997) commented on the paucity of studies with control groups, large enough numbers of subjects and adequate length of follow-up. We have also been looking at this area of significant clinical need and believe a major difficulty is the longitudinal perspective required in terms of outcome, as experience suggests clinical improvements take several years to be realised (Drake et al, 1993). This makes planning and financing randomised controlled trials in an area with many potential confounding factors and a population notoriously non-compliant very difficult indeed.

In light of recent calls for the development of high-quality clinical databases (Black, 1997), surely it is more realistic to develop case registers of patients with severe mental illness and substance misuse and seek to use these to follow people over a long time period. While randomised controlled trials should remain as the gold standard in testing specific interventions for specific populations, the complexities of managing patients (including those often excluded from randomised controlled trials) over many years in an area where progress is often slow might be better measured by a more naturalistic methodology.

Black, N. (1997) Developing high quality clinical databases British Medical journal, 315. 381-382.

Drake, R. E., Bartels, S. J., Teague, G. B., et al (1993) The treatment of substance abuse in severely mentally ill patients. Journal of Nervous and Mental Disease, 18, 606-611.

Johnson, S. (1997) Dual diagnosis of severe mental illness and substance misuse: a case for specialist services? British Journal of Psychiatry, 171. 205-208.

R. Laugharne Section of Community Psychiatry, St George's Hospital Medical School, Jenner Wing, Cranmer Terrace, London SWI7 ORE

\section{Subjective quality of life and drug treatment for schizophrenia}

Sir: Quality of life of people with schizophrenia receiving drug treatment is a poorly researched area. The study by Franz et al (1997) concludes that the significantly better quality of life they reported in people receiving atypical neuroleptics was independent of both psychopathology and the side-effects of the drugs. Instead, the difference in subjective quality of life was related to the differences in the intrinsic properties of the two classes of drugs, that is pharmacogenic or akinetic depression due to conventional antipsychotics and improvement in mood and drive with the atypical neuroleptics. The fact that these effects indicate nothing other than negative and extrapyramidal symptoms immediately makes the above conclusion contradictory.

The concept of quality of life in people with schizophrenia is not well understood. According to the model proposed by Awad \& Hogan (1994), the most important factors that bring about a change in quality of life (including subjective quality of life) are changes in symptoms and in the side-effects of the drugs. Surprisingly, Franz et al (1997) could not demonstrate any influence of these two critical factors on the ratings of quality of life they reported. It is possible that the cross-sectional design of their study as well as a certain arbitrariness in changing neuroleptic (from conventional to atypical and from one type of atypical neuroleptic to another within a period as short as 10 days) may have interfered with the expected negative correlation between scores of psychopathology and quality of life. Furthermore, time of administration of the Positive And Negative Syndrome Scale is not known, and no standardised instrument was used to measure the extrapyramidal symptoms. Thus, the effect of atypical neuroleptics on subjective quality of life need not be independent of symptoms and of the sideeffects of the drugs.

Awad, A. G. Hogan, T. P. (1994) Subjective response to neuroleptics and quality of life: implications for treatment outcome. Acto Psychiatrico Scondinovico. 89 (suppl. 380). 27-32.

Franz, M., Lis, S., Plüddemann, K., et el (1997) Conventional versus atypical neuroleptics: subjective quality of like in schizophrenic patients. British journol of Psychiotry. 170. 422-425.

S. Sengupta, N. Kar Department of Psychiatry, Kasturba Medical College, Maniapal, 576 119, Karnataka, India

\section{One hundred years ago}

\section{Mental Disease Out-Patients}

We have pleasure in drawing attention to the fact that an out-patient department for mental disease has now been established for upwards of two years at Sheffield, under Dr. Crochley Clapham.

Dr. Clapham reports that it has been successful in attracting a considerable number of patients, in a fair proportion of whom he believes that the necessity of asylum treatment has been avoided, therein confirming the experience of a similar department at St. Thomas' Hospital. 